\title{
"Analisis Faktor Penurunan Gangguan Saluran Udara Tegangan Menengah (SUTM) Pada Penyulang Parangbanoa"
}

\author{
Adriani $^{1} 1$ \\ Prodi Teknik Elektro Fakultas Teknik Unismuh Makassar \\ E_mail :adriani@unismuh.ac.id
}

\begin{abstract}
ABSTRAK
Kehandalan sistem tenaga listrik merupakan salah satu hal yang sangat diperhatikan demi menjaga kinerja tigapilar utama PT. PLN (Persero). Permasalahan yang sering terjadi pada bidang distribusi adalah gangguan pada penyulang. Tujuan dari Penelitian ini bertujuan Untuk mengetahui penyebab terjadinya gangguan penyulang trip pada penyulang parangbanoa di PT. PLN (Persero) ULP Kalebajeng.Permasalahan yang sering terjadi pada bidang distribusi adalah gangguan penyulang. .Berdasarkan hasil Output ArcGIS (Geometry Informindo System) potensi penyebab terjadinya gangguan trip pada penyulang parangbanua adalah pohon dan tanaman yang mengenai SUTM, binatang pada jaringan, komponen JTM yang sudah rusak, isolator pecah, dan sambungan yang kurang erat sehingga menimbulkan suhu yang panas.Kegiatan pemeliharaan yang dilakukan terbagi pemeliharaan terpadu. saving yang diperoleh sebesar $7.418 \mathrm{kWh} /$ minggu, dan Gain yang diperoleh bisa mencapai Rp. 10.882.206,- / minggu, sedangkan manfaat yang didapatkan berupa penurunan jumlah gangguan trip penyulang,.
\end{abstract}

Kata kunci (key words):ArcGIS, Gangguan SUTM, Akibat SUTM. 


\section{PENDAHULUAN}

PT. PLN (Persero) merupakan perusahaan Badan Usaha Milik Negara (BUMN) yang bergerak di bidang jasa ketenagalistrikan dan mempunyai tugas utama untuk mendistribusikan energi listrik untuk pelanggan di seluruh wilayah Indonesia. Dalam menjalankan tugasnya, PT. PLN (Persero) dituntut untuk selalu menjaga kontinuitas dan kuantitas dari proses mendistribusikan energi listrik. Demi menjaga kualitas dan kontinuitas pendistribusian tenaga listrik maka PT.PLN (Persero) perlu memperhatikan beberapa hal khususnya dalam bidang distribusi, yaitu menjaga keandalan sistem distribusi. Demi menjaga kualitas dan kontinuitas pendistribusian energi listrik dapat dilakukan dengan meminimalisir gangguan penyulang yang dapat mengakibatkan trip.

Menyediakan tenaga listrik agar tetap terjaga kualitas dan kontinuitasnya merupakan tugas utama dari PT. PLN (Persero). Tapi dalam realitanya hal ini bukanlah hal yang mudah karena banyaknya permasalahan yang sering dihadapi dilapangan.

Dalam pelayanan kepada masyarakat PT. PLN (Persero) mengacu kepada tiga pilar kinerja utama. Tiga pilar utama tersebut ntara lain :

1. Kehandalan Sistem TenagaListrik

2. SusutDistribusi

3. Umur Piutang

Berdasarkan tiga pilar tersebut, kehandalan sistem tenaga listrik merupakan salah satu hal yang sangat diperhatikan demi menjaga kinerja tigapilar utama PT. PLN (Persero).

Permasalahan yang sering terjadi pada bidang distribusi adalah gangguan penyulang. Gangguan penyulang merupakan masalah yang memberikan pengaruh yang besar terhadap kinerja perusahaan. Hal ini mengakibatkan menurunnya pelayanan terhadapmasyarakat.

ULP Kalebajeng adalah salah satu ULP yang dibawahi oleh UP3 Makassar Selatan yang memiliki beberapa penyulang. Seluruh penyulang yang ada di ULP Kalebajeng dimulai dari pertengahan jaringan, yang menjadi batasan antar ULP ditandai dengan titik transaksi $\mathrm{kWh}$ exim (export-import) sampai ujung penyulang.

\section{RUMUSAN MASALAH}

Berdasarkan latar belakang masalah yang diuraikan sebelumnya, maka rumusan masalah yang diajukan dalam penelitian ini adalah :

1. Bagaimana caramengatasi terjadinya gangguan penyulang trip pada Penyulang Parangbanoa ULP Kalebajeng.

2. Bagaiamana cara menganalisa gangguan dengan cepat dengan menggunakan Apliksi ArcGIS (Geometry Informindo System)

3. Berapa besar kerugian yang diakibatkan akibat gangguan penyulang parangbanoa.

\section{TUJUAN PENULISAN}

Penelitian ini bertujuan untuk menjawab rumusan masalah yang telah dikemukakan yaitu :

1. Untuk mengetahui penyebab terjadinya gangguan penyulang trip pada penyulang parangbanoa di PT. PLN (Persero) ULP Kalebajeng

2. Untuk mendapatkan gangguan dengan cepat di Penyulang Parangbanoa dengan menggunakan Apliksi ArcGIS (Geometry Informindo System) 
3. Untuk menurunkan gangguan trip pada penyulang parangbanoa ULP Kalebajeng.

4. Untuk meningkatkan keandalan jaringan sehingga dapat meningkatkan kepuasan pelaggan.

\section{TINJAUAN PUSTAKA}

\section{Teori Dasar Jaringan Distribusi}

Sistem Distribusi merupakan bagian dari sistem tenaga listrik. Sistem distribusi ini berguna untuk menyalurkan tenaga listrik dari sumber daya listrik besar (Bulk Power Source) sampai ke konsumen. Jadi fungsi distribusi tenaga listrik adalah;

1) Pembagian atau penyaluran tenaga listrik ke beberapa tempat (pelanggan)

2) Merupakan sub sistem tenaga listrik yang langsung berhubungan dengan pelanggan, karena catu daya pada pusat-pusat beban (pelanggan) dilayani langsung melalui jaringan distribusi.

Tenaga listrik yang dihasilkan oleh pembangkit tenaga listrik besar dengan tegangan dari $11 \mathrm{kV}$ sampai $24 \mathrm{kV}$ dinaikkan tegangannya oleh gardu induk dengan transformator penaik tegangan menjadi $70 \mathrm{kV}, 154 \mathrm{kV}, 220 \mathrm{kV}$ atau $500 \mathrm{kV}$ kemudian disalurkan melalui saluran transmisi. Tujuan menaikkan tegangan ialah untuk memperkecil kerugian daya listrik pada saluran transmisi, dimana dalam hal ini kerugian daya adalah sebanding dengan kuadrat arus yang mengalir (I2.R). Dengan daya yang sama bila nilai tegangannya diperbesar, maka arus yang mengalir semakin kecil sehingga kerugian daya juga akan kecil pula.

\section{Pengelompokan Jaringan Distribusi Tenaga Listrik}

Untuk kemudahan dan penyederhanaan, lalu diadakan pembagian serta pembatasan-pembatasan sebagai berikut:

1. Daerah I : Bagian pembangkitan(Generation)

2. Daerah II : Bagian penyaluran (Transmission), bertegangan tinggi (HV,UHV,EHV)

3. Daerah III : Bagian Distribusi Primer, bertegangan menengah (6 atau $20 \mathrm{kV}$ ).

4. Daerah IV : (Di dalam bangunan pada beban/konsumen), Instalasi, bertegangan rendah.

\section{Klasifikasi Jaringan Distribusi Tegangan Menengah \\ Berdasarkan Tegangan Pengenal}

Berdasarkan tegangan pengenalnya sistem jaringan distribusi dibedakan menjadi dua macam, yaitu :

a. Sistem jaringan tegangan primer atau Jaringan Tegangan Menengah (JTM), yaitu berupa Saluran Kabel Tegangan Menengah (SKTM) atau Saluran Udara Tegangan Menengah (SUTM). Jaringan ini menghubungkan sisi sekunder trafo daya di Gardu Induk menuju ke Gardu Distribusi, besar tegangan yang disalurkan adalah $6 \mathrm{kV}, 12 \mathrm{kV}$ atau $20 \mathrm{kV}$.

b. Jaringan tegangan distribusi sekunder atau Jaringan Tegangan Rendah (JTR), salurannya bisa berupa SKTM atau SUTM yang menghubungkan Gardu

Distribusi/sisi sekunder trafo distribusi ke konsumen. Tegangan sistem yang digunakan adalah 220 Volt dan 380 Volt. 
Berdasarkan Konfigurasi Jaringan Primer

a. Jaringan distribusi pola radial

b. Jaringan distribusi pola loop

c. Jaringan distribusi pola grid

d. Jaringan distribusi pola spindle

\section{ArcGIS (Geometry informindo system)}

Menurut Prahasta, 2007,p1, ArcGis(Geometry informindo system) adalah sebuah sistem yang berbasis komputer yang digunakan untuk menyimpan informasi informasi geografis. Sistem informasi geometri ini dirancang untuk mengumpulkan, menyimpan, serta menganalisis objek-objek dan fenomenafenomena yang mengetengahkan lokasi geografis sebagai karakteristik yang penting atau kritis bertujuan untuk dianalisis. Dengan demikian, Sistem Informasi Geografis adalah sistem komputer yang memiliki empat kemampuan dalam menangani data yang bereferensi geografis, yaitu: masukan, keluaran, manajeman data (penyimpanan dan pemanggilan data), serta analisis dan manipulasi data.

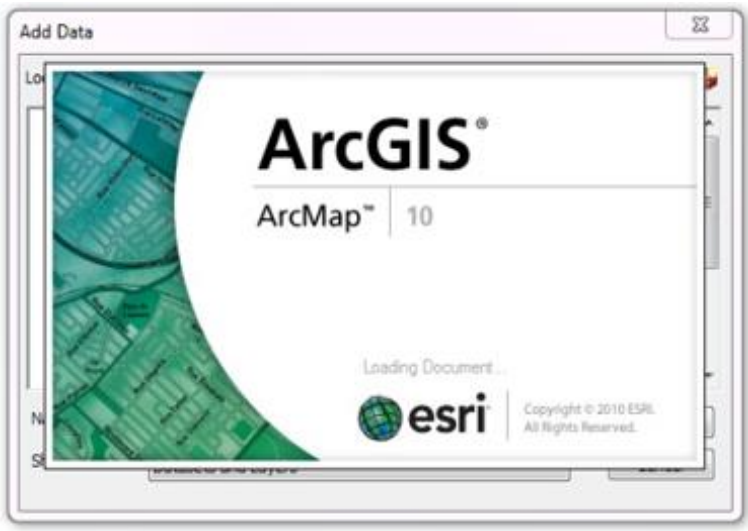

Gambar 2.7. Icon Arc GIS

\section{ETODE PENELITIAN}

Waktu Dan Tempat Penelitian

Waktu :Penelitian dilaksanakan pada tanggal 4 Juli 2020 sampai dengan Minggu pertama bulan Agustus 2020.
Tempat Penelitian : Tempat penelitian ini dilaksanakan pada Kantor PT PLN (Persero) Unit Layanan Pelanggan Kalebajeng, Kabupaten Gowa.

Alat dan bahan

1. Laptop

2. Perangkat lunak SINOPI (Sistem Informasi Operasi Distribusi)

3. Perangkat lunak ArcGIS (Geometry Informindo System)

4. Termovision

5. Kamera

6. Pulpen dan kertas

\section{Langkah langkah penelitian}

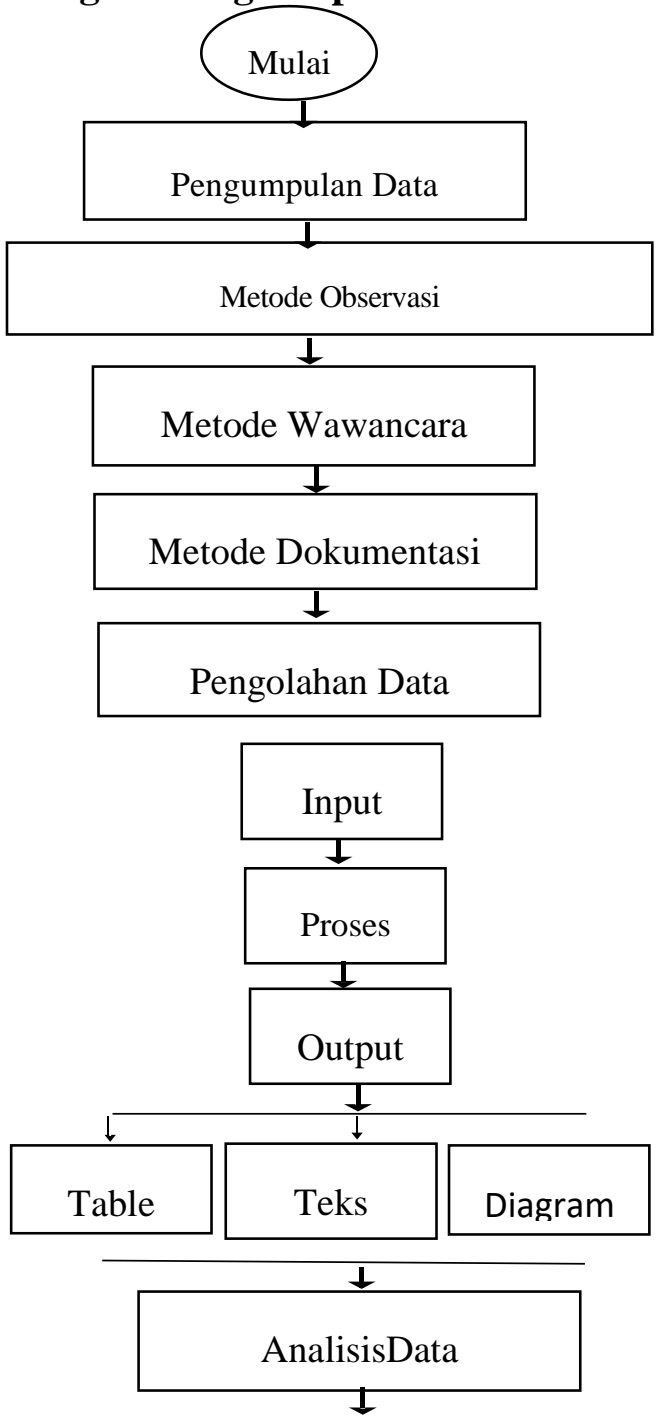




\section{HASIL DANPEMBAHASAN}

\section{Penyulang Bermasalah}

Unit Layanan Pelanggan Kalebajeng memiliki 5 penyulang. Dalam tahun 2019 total gangguan penyulang yang terjadi pada Area kerja Unit Layanan Pelanggan Kalebajeng adalah 233 kali gangguan. Berikut data gangguan penyulang ULP Kalebajeng baik permanen maupun temporer.

Pengolahan data denganaplikasi Arc GIS (Geometry informindo system):

Dari faktor korelasiyang dihasilkan oleh ArcGIS tersebutdidapatkanfaktor dominannyadengancaramelihatnilaipearsonc orrelationyangdiurutkanmenjadi tiga besar begitujuga denganakibatgangguanlama padamdanenergytak tersalurkan.

Dari faktor yang didapatkan dari hasil ArcGIS (Geometry informindo system) tesebut didapatkan beberapa faktor gangguan yang terjadi yang berakibat lama padam dan eneregi yang tidak tersalurkan

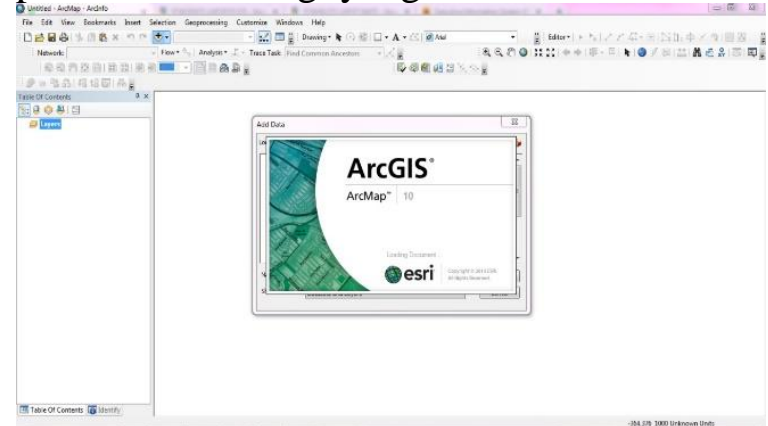

Banyak Kali Padam

\section{Data Koefisien \\ Banyak Kali Padam}

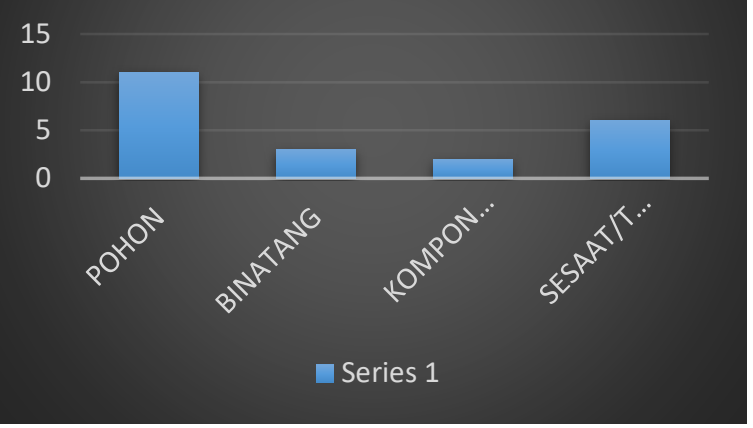

Lama Padam (Menit)

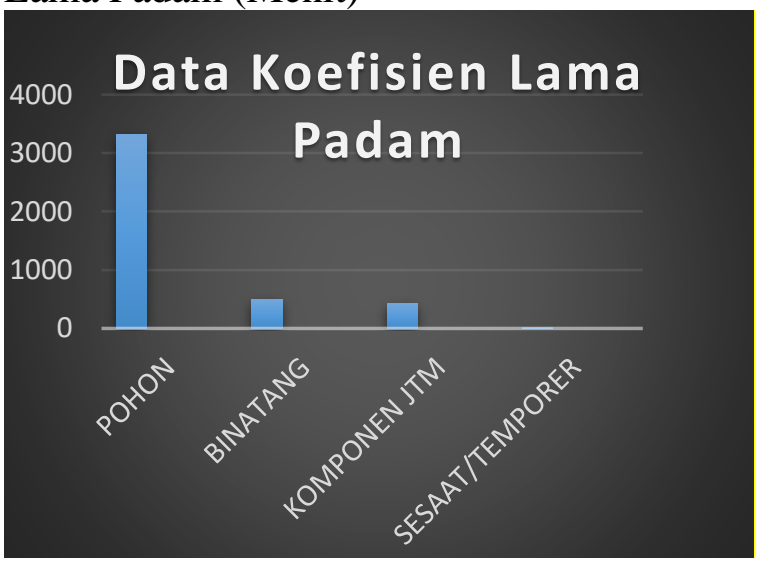

$\mathrm{kWh}$ yang tidak tersalurkan

\section{Data Koefisien kWh Tidak Tersalurkan}

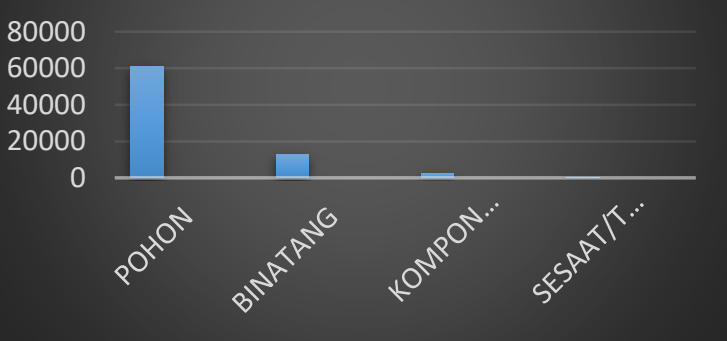

\section{Analisis Tindakan}

\section{a. Pemeliharaan ROW (Right ofWay)}

Jarak aman sesuai dengan standar yang ada adalah $2.5 \mathrm{M}$ dari ROW dan tidak membahayakan jaringan sehingga 
apabila terjadi hujan atau angin kencang maka pohon tidak akan mengenai JTM. Hasil inspeksi ROW pada penyulang Parangbanua banyak ditemukan daerah yang sangat berpotensi menyebabkan gangguan. Dalam menyelesaikan permasalahan gangguan yang disebbakan kaerena pohon ini dilakukan perampalan rutin, dan memonitoring perampalanpohon menggunakan Aplikasi Monitoring ROW (MON.ROW).

\section{b. Penggantian Penghantar Terburai}

Untuk inspeksi kondisi kawat konduktor yang diperhatikan adalah konduktor yang terburai dan andongan yang kendor. Pada penyulang Parangbanua ditemukan beberapa gawang yang penghantarnya terburai dan kendor khususnya pada kp.Nyulu terdapat 3 gawang, dan paranglompoa 2 gawang. Sehingga harus dilakukan penggantian kawat penghantar yang baru dengan memotong kawat yang terburai kemudian menyambungkan dengan kawat yang baru menggunakan join slip. Kemudian mengencangkan andongan sehingga kawat penghantar tidakkendor.

\section{c. Penggantian Isolator Pecah}

Pada penyulang parangbanoa bagian poros penyulang ditemukan 28 buah isolator tumpu yang pecah dan 4 buah isolotor aspan khususnya dari LBS manual Tanah Karaeng - DCC Paranglompoa. Isolator pecah merupakan salah satu penyebab terjadinya gangguan penyulang. Sehingga harus segera dilakukan pergantian dengan isolator yang baru.

\section{d. Meluruskan Tiang Miring}

Pada penyulang Parangbanua khususnya pada poros penyulang ditemukan 4 titik tiang miring yaitu antara LBS manual Tanah Karaeng - DCC Pattallikang tepatnya di Kp. Pattallikang, antara LBS manual
Mangngepang - DCC Paranglompoa tepatnya di Kp. Sapaya, Kp. Nyulu, Kp. Kalukaluku. Tiang miring ini disebabkan karena beberapa faktor, seperti Skur putus, tiang berada di pinggir jurang, tanah tidak rata sehingga dapat berpotensi mengakibatkan tiang menjadi miring. Tiang miring ini di pelihara dengan menggali tanah dimana tiang itu berdiri dengan posisi miring sehingga ada ruang untuk tiang dapat berdiri tegak, kemudian Memasang skur pada tiang, dan mensetting skur sehingga tiang berdiri tegak. Ketika tiang sudah berdiri tegak dilakukan pengecoran pada bagian bawah tiang agar lebih kuat dan mencegah terjadinyalongsor.

\section{e. Mengencangkan Andongan JUTM Kendor}

Pada Penyulang Parangbanua di temukan 2 lokasi yang andongan JUTM kendor yaitu antara LBS manual Mangngempang - DCC Paranglompoa tepatnya di Kp. Kalukaluku. Setelah melakukan inspeksi maka dilakukan pengencangan andongan JUTM yang kendor dengan menggunakan Powerpull.

\section{f. Perbaikan Traves JUTM Miring}

Pada penyulang parangbanoa ditemukan satu titik tiang dengan kondisi traves miring di kp. Rannaloe antara DCC Pattalikang dan LBS Manual Mangempang (percabangan FCO Buakkang). Traves miring ini dapt berpotensi mengakibatkan terjadinya flashover apabila terjadi hujan yang dapat menyebabkan penyulang trip. Sehingga harus dilakukan pergantian ARM Brace (siku) dengan yang baru

\section{g. Pengkuran Suhu JUTM Dengan Menggunakan Thermovision}

Salah satu upaya untuk mengidentifikasi gangguan pada Jaringan Udara Tegangan Menengah (JUTM) terkhusus pada penyulanag parangbano 
adalah dengan rutin melakukan pengukuran suhu dengan menggunakan Thermovision yang mana bertujuan untuk mngetahui suhu panas pada jumperan, baut-baut yang longgar, konduktor yang hampir putus.

Setelah melakukan Inspeksi dan menindaklanjuti hasil inspeksi dengan melakukan pemeliharaan, selanjutnya melakukan monitoring terhadap kondisi penyulang Parangbanua untuk mengetahui keandalan penyulang setelah dilaksanakannya pemeliharaan dengan harapan terjadinya penurunan kali gangguan pada penyulang.

\section{PENUTUP}

\section{Kesimpulan}

Kesimpulan yang dapat diperoleh dari laporan penelitian ini adalah :

1)Dari hasil penelitian didapatkan kemungkinan utama penyebab terjadinya trip penyulang selama ini adalah gangguan pohon dan kerusakan peralatan komponen.

2)Berdasarkan hasil Output ArcGIS

(Geometry Informindo System) potensi penyebab terjadinya gangguan trip pada penyulang parangbanua adalah pohon dan tanaman yang mengenai SUTM, binatang pada jaringan, komponen JTM yang sudah rusak, isolator pecah, dan sambungan yang kurang erat sehingga menimbulkan suhu yang panas.

3)Kegiatan pemeliharaan yang dilakukan terbagi pemeliharaan terpadu. Kegiatan pemeliharaan terpadu ini bertujuan mengurangi kemungkinan penyebab gangguan penyulang yaitu rampal pohon, pembersihan jaringan dari layangan, pengencangan baut-baut pada gardu, penggantian komponen peralatan yang sudah rusak seperti FCO dan Lightning Arrester, serta isolator yang pecah

4)Setelah melakukan pemeliharaan, saving yang diperoleh sebesar $7.418 \mathrm{kWh} /$ minggu, dan Gain yang diperoleh bisa mencapai Rp.
10.882.206,- / minggu, sedangkan manfaat yang didapatkan berupa penurunan jumlah gangguan trip penyulang, meningkatkan keandalan jaringan dan mutu pelayanan pelanggan serta meningkatkan $\mathrm{kWh}$ jual penyulangParangbanua.

\section{Saran}

Saran yang dapat diberikan adalah sebagai berikut :

1) Memaksimalkan isnpeksi penyulang berdasarkan jadwal yang telah dibuat sesuai denga target WIG ULP Kalebajeng

2) Memonitoring rampal pohon berdasarkan jadwal yang telah dibuat untuk mengurangi potensi gangguan penyulang yang disebabkan karena pohon.

3) Melakukan inspeksi menggunakan Thermovision secara terjadwal untuk mengetahui kondisi komponen dan material penyulang

4) Melakukan kegiatan pemeliharaan terpadu secara terjadwal setiap bebrapa bulan sekali

5) Mengganti semua sambungan jumperan dengan mengguanakan $\mathrm{CCO}$ atau H-Type

\section{DAFTAR PUSTAKA}

Daman suswanto.2009. Sistem Distribusi Tenaga Listrik. Universitas Negeri Padang

Marsudi, Djiteng. 2006.Operasi Sistem Tenaga Listrik. Penerbit Graha Ilmu.Jakarta

PT. PLN (Persero), 2014.Sistem Distribusi Tenaga Listrik. Penerbit PT. PLN (Persero).Jakarta

PT. PLN (Persero). 2019. Gangguan Penyulang Distribusi $20 \mathrm{kV}$. Penerbit PT. PLN (Persero) UIKL Sulawesi.Manado

PT. PLN (Persero).2020. Unit Layanan Pelanggan Kalebajeng. Data Gangguan Saluran Udara Tegangan Menengah 
Vertex Elektro, Vol.13, No.01, Tahun 2021 ( Februari)

p-ISSN. 1979-9772 e-ISSN. 2714-7487

Stevenson Jr, W. D. 1988. Analisa

SistemTenaga. Penerbit Erlangga.

Jakarta

RendiEka Putra. Gangguan

SutmDiWilayah

KerjaPT.PLN(Persero) RayonKuranji

Stevenson J,WilliamD. (1993),Analisa

SistemTenaga Listrik,Edisikeempat.

Erlangga. Jakarta

SPLNNo.72.1987.SpesifikasiDesainUntukJarin

gan Tegangan Menengah (JTM)

danJaringanTeganganRendah(JTR). Jakarta :

Perusahaan UmumListrikNegara.

Wordpress. 2013. Jaringan Distribusi. https://armanbacktrack5.wordpress.com/2013/02

/25/jaringan-distribusi/(Maret

2018) 